\title{
ACE I/D but not AGT (-6)A/G polymorphism is a risk factor for mortality in ARDS
}

\author{
M. Adamzik*,\#, U. Frey*,\# , S. Sixt", L. Knemeyer*, M. Beiderlinden\#, \\ J. Peters ${ }^{\#}$ and W. Siffert*
}

ABSTRACT: The intrapulmonary renin-angiotensin system via tissue concentration of angiotensin II or bradykinin may have multiple effects on pulmonary pathophysiology. Therefore, it was investigated whether the presence of the $D$ allele of the angiotensinconverting enzyme (ACE) insertion/deletion (I/D) polymorphism or the $A$ allele of angiotensinogen (AGT) promoter polymorphism (-6)A/G are independent risk factors for 30-day survival in acute respiratory distress syndrome (ARDS) patients.

In a prospective study, adults (Germans of Caucasian ethnicity) with ARDS ( $n=84)$ were recruited from the current authors' intensive care unit and genotyped for the ACE I/D and the AGT (-6)A/G polymorphisms, as were 200 healthy Caucasian controls.

Mortality was increased in the ACE DD genotype compared with the I allele, and the ACE I/D polymorphism was an independent prognostic factor for 30-day survival. Patients with a homozygous DD genotype were at highest risk for death (hazard ratio 5.7; 95\% confidence interval 1.7-19.2) compared with the II genotype. In contrast, the AGT (-6)A/G polymorphism was neither associated with an increased risk for development of ARDS nor with outcome.

In patients with acute respiratory distress syndrome, the angiotensin-converting enzyme insertion/deletion polymorphism but not the angiotensinogen (-6)A/G promoter polymorphism is an independent risk factor with a pronounced effect on 30-day survival.

KEYWORDS: Acute respiratory distress syndrome, angiotensin-converting enzyme insertion/ deletion polymorphism, intrapulmonary renin-angiotensin system

A cute respiratory distress syndrome (ARDS) is characterised by increased capillary-alveolar permeability, hypoxaemia, reduced lung compliance, diffuse bilateral pulmonary infiltrates and the need for mechanical ventilation. ARDS remains an important cause of death in the intensive care unit (ICU) and few specific therapies are available. Factors predicting the onset or severity of this syndrome are not well known, but the low incidence of ARDS within the relatively large group of patients at risk suggests the interaction of genetic and environmental factors [1, 2]. The early stages of ARDS are characterised by a high permeability pulmonary oedema, alveolar epithelial cell loss and neutrophil infiltration, which may progress to significant alveolar and interstitial remodelling and fibrosis. Experimental evidence suggests that activation of the pulmonary renin-angiotensin system (RAS) may influence the pathogenesis of ARDS via mechanisms affecting vascular permeability [3], vascular tone [4], fibroblast proliferation [5] and by decreasing alveolar epithelial cell survival [6].
Hence angiotensin (AT)-II may play a major role in the pathogenesis of ARDS. AT-II is generated through the proteolytic cleavage of angiotensinogen (AGT), which is primarily synthesised in the liver and, to a lesser extent, in the kidney, brain, heart, adrenal grands, fat and vascular walls $[7,8]$. AGT is first converted by renin to the decapeptide AT-I. Thereafter, angiotensin-converting enzyme (ACE) converts AT-I to AT-II. However, ACE also degrades bradykinin, which impacts on vascular tone, vascular permeability and cardiac function [9]. Accordingly, bradykinin could also contribute to the pathogenesis of ARDS.

Approximately $47 \%$ of the variance in plasma ACE activity is explained by a common insertion/deletion (I/D) polymorphism located in intron 16 of the ACE gene, the $\mathrm{D}$ allele being associated with increased ACE activity [10]. Circulating ACE is often decreased in patients with ARDS [11]. However, this may reflect attenuated enzyme release from damaged pulmonary vascular endothelium and may not represent ACE activity in other lung compartments. In fact, an increased ACE activity has been
AFFILIATIONS

*Institut für Pharmakogenetik, and

${ }^{\#}$ Klinik für Anästhesiologie und

Intensivmedizin, Universität

Duisburg-Essen, Universitätsklinikum

Essen, Essen, Germany.

CORRESPONDENCE

M. Adamzik

Klinik für Anästhesiologie und

Intensivmedizin

Universitätsklinikum Essen

Hufelandstr. 55

D-45122 Essen

Germany

Fax: 492017235949

E-mail: michael.adamzik@uni-

essen.de

Received:

April 032006

Accepted after revision:

November 032006

STATEMENT OF INTEREST

None declared.

European Respiratory Journal

Print ISSN 0903-1936

Online ISSN 1399-3003 
reported in bronchoalveolar lavage (BAL) fluid, despite a decrease in circulating concentrations [11]. In line with this latter observation, the transpulmonary gradient and circulating concentrations of AT-II are increased in patients with ARDS [12], and activation of the circulating RAS, with a preservation of the transpulmonary gradient, was also found in critically ill patients [13]. While ACE is mainly derived from endothelial cells [14] and the lung represents the body's largest endothelial surface, interindividual differences in ACE activity may affect the susceptibility for, and survival during, ARDS [15]. Since the plasma concentration of AGT is close to the Michaelis constant of the enzymatic reaction between renin and AGT, a rise in plasma AGT levels can lead to a parallel increase in AT-II formation [16].

The human AGT gene harbours a (-6)A/G promoter polymorphism [17]. The (-6)A allele displays increased promoter activity compared with $(-6) \mathrm{G}$, with concomitantly increased plasma AGT levels [18]. Thus, if AT-II is crucial for the pathogenesis of ARDS, genotypes of the AGT (-6)A/G polymorphism could also affect the susceptibility for, and survival during, ARDS.

Therefore, it was investigated whether genotypes of the ACE I/ D polymorphism or the $A G T$ (-6)A/G promoter polymorphism are independent risk factors for 30-day survival in patients with ARDS.

\section{METHODS}

\section{Study population}

The present study was reviewed and approved by the Ethics Committee of the University Hospital Essen (Essen, Germany). Over a period of $2 \mathrm{yrs}$, patients admitted to a specialised ICU of the University Hospital Essen were considered eligible for the study if they fulfilled the joint American/European Consensus Committee criteria for ARDS [19], had no previous history of ARDS and written informed consent was obtained. All patients ( 43 males, 41 females; mean age $43 \pm 16$ yrs) were Germans of Caucasian ethnicity. The specific clinical disorder which evoked ARDS was determined over the first $24-48 \mathrm{~h}$ after the patient met ARDS criteria. As in other studies, some patients had more than one potential predisposing clinical condition associated with the development of ARDS [20]. However, the primary condition responsible was determined by investigators after careful review of the clinical and laboratory data. The primary clinical disorders included pneumonia, sepsis and other disorders (e.g. trauma, aspiration). Pneumonia was defined as evidence of primary lung infection from bacterial, viral, fugal or parasitic infection as diagnosed by medical history, Gram's stain and cultures of tracheal aspirate or BAL specimen. The term sepsis syndrome was used as defined by BONE [20]. Patients who met criteria for both sepsis syndrome and pneumonia were classified as pneumonia, with the assumption being that pneumonia evoked the sepsis syndrome. Clinical and demographic data at baseline, including lung injury score (LIS), Simplified Acute Physiology Score (SAPS) [21] and the Sequential Organ Failure Assessment (SOFA) score [22], were calculated over the first 24-48 $\mathrm{h}$ after the patient met ARDS criteria. Patients were categorised as survivors if they were alive 30 days after the diagnosis of ARDS or discharged from the hospital without requirement of mechanical ventilation.
The control sample consisted of 200 healthy Caucasian individuals of either sex who were recruited at the local Department for Transfusion Medicine, University Hospital Essen. All samples were collected at random from subjects donating blood and the details of the sample have been published previously [23].

\section{Determination of genotypes}

DNA was extracted from whole blood samples by modified phenol-chloroform extraction. ACE genotype was determined by three-primer PCR amplification as described previously [24], performed by staff blinded to all subject data. This method yields amplification products of $84 \mathrm{bp}$ for the $\mathrm{D}$ allele and $65 \mathrm{bp}$ for the I allele, and products were visualised on polyacrylamide gels. The homozygous insertion (II) genotype was confirmed by repeat PCR in the absence of a primer for the I allele. All samples were randomised, genotyped and results replicated by two independent researchers. For genotyping the AGT (-6)A/G polymorphism, PCR was carried out using primers AGT-ProSE 5'-CTTCTGGCATCTGTCCTTCTGG-3' biotinylated and primer AGT-Prom-AS 5'-CCTAGCCCACAGCTCAGTTACATC-3', resulting in a $200 \mathrm{bp}$ fragment. Genotypes were determined using pyrosequencing [25] with sequencing primer AGT-Pro-Seq 5'-GGCAGCTTCTTCCCC-3'.

\section{Statistical analysis}

The clinical outcome analysed in the present study was survival of the first 30 days dependent on ACE and AGT genotypes. Kaplan-Meier plots and the log-rank test for trend were used to evaluate the relationship between genotypes and clinical outcome from the date of the primary diagnosis to the end of follow-up. Log-rank tests for ACE genotypes were performed using all three genotypes, unless stated otherwise. The power $(1-\beta)$ of the clinical outcome analysis was 0.87 . The impact of sex, SAPS, SOFA, LIS, age, body mass index (BMI), positive end-expiratory pressure (PEEP), ratio of arterial oxygen tension and inspiratory oxygen fraction $\left(\mathrm{Pa}_{2} \mathrm{O}_{2} / \mathrm{FI}, \mathrm{O}_{2}\right)$, and $A C E$ genotypes as prognostic factors for the clinical outcome were analysed by stepwise multivariate Cox regression analysis. Nonsignificant variables $(\mathrm{p}>0.05)$ were removed stepwise from the model. Hazard ratios (HR) and 95\% confidence intervals (CI) were calculated from the Cox regression model including all remaining factors for multivariate analysis and for the indicated factor for univariate analysis. Contingency tables and the Pearson's Chi-squared test were used for categorical variables using $A C E$ and $A G T$ genotypes. Since the $A C E \mathrm{I} / \mathrm{D}$ polymorphism appeared to show a gene-dose effect, ANOVA was used for comparison of continuous parametric variables, where appropriate. The Kruskal-Wallis test was used for continuous nonparametric variables. The Hardy-Weinberg equilibrium was tested by a goodness-of-fit Chi-squared test. Differences with a p-value $<0.05$ were regarded as significant. Continuous variables are given as mean $\pm \mathrm{SD}$, as indicated.

\section{RESULTS}

Using Kaplan-Meier estimates to compare outcome, 30-day survival was significantly associated with $A C E$ genotypes $(\mathrm{p}=0.011$; fig. 1$)$ with an apparent gene-dose effect. Patients homozygous for the ACE DD genotype displayed a significantly higher risk for death than patients with II genotypes, 


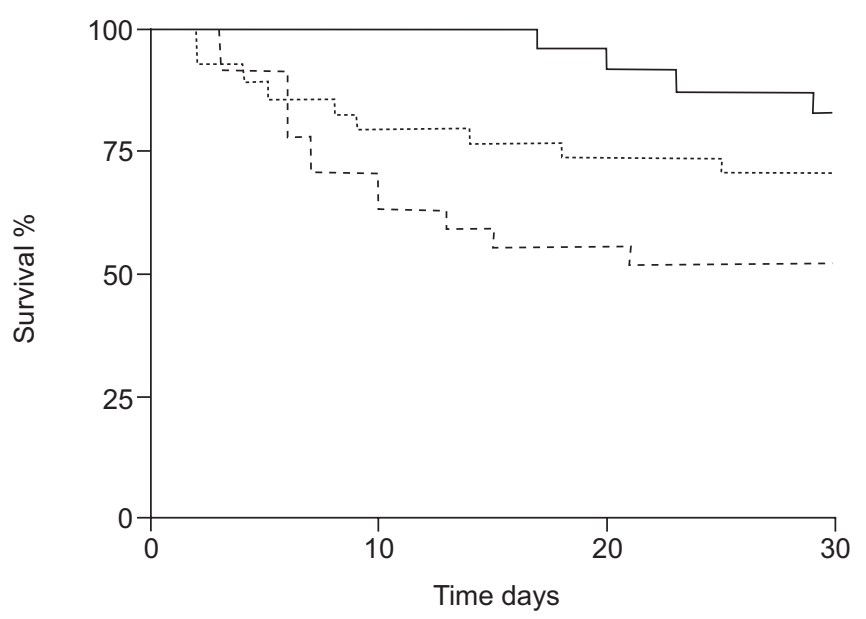

FIGURE 1. Thirty-day survival in patients with acute respiratory distress syndrome dependent on genotypes of the angiotensin-converting enzyme insertion/deletion (I/D) polymorphism. Kaplan-Meier estimates were used to calculate probabilities of 30-day survival, which was significantly increased in the II genotypes compared with carriers of a $\mathrm{D}$ allele $(p=0.011)$. — : II; .......... ID; ---- : DD.

with heterozygous patients being at intermediate risk (HR: DD versus II: 3.6 (95\% CI 1.3-8.7), $\mathrm{p}=0.011$; ID versus II: 2.2 (0.7-6.1), $\mathrm{p}=0.162)$. Thirty-day survival rates were $73.2 \%$ for II, $64.0 \%$ for ID and $50.0 \%$ for DD genotypes, respectively (fig. 1). In contrast, no such association was found for AGT genotypes (fig. 2).

Multivariate proportional hazard analysis including age, sex, LIS, BMI, PEEP, SAPS and $\mathrm{Pa}_{1} \mathrm{O}_{2} / \mathrm{FI}_{1} \mathrm{O}_{2}$ as covariates revealed the $A C E \mathrm{I} / \mathrm{D}$ polymorphism to be the most important and independent prognostic factor for 30-day survival. Homozygous DD subjects were at highest risk for death (HR 5.7 (95\% CI 1.7-19.2), $\mathrm{p}=0.005)$ compared with II genotypes (table 1).

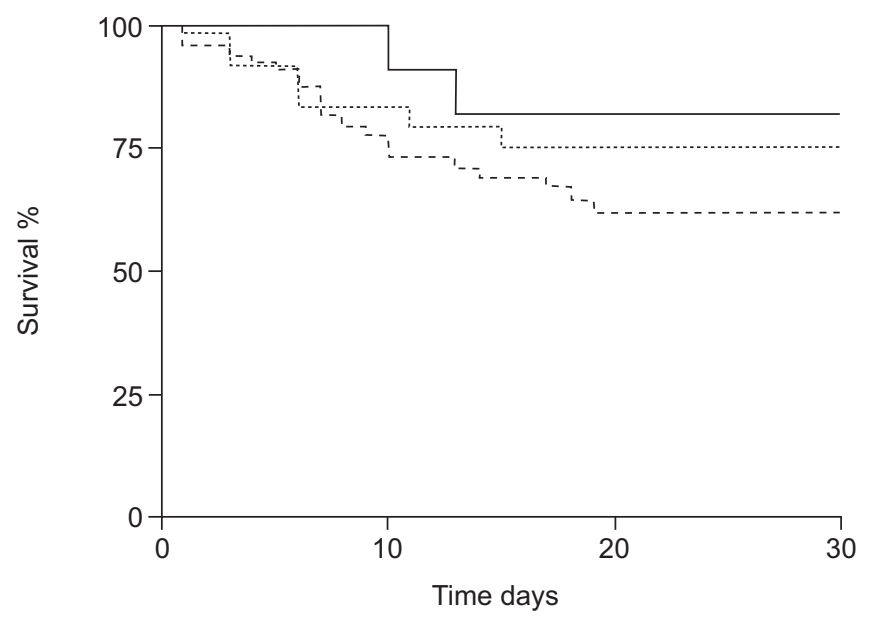

FIGURE 2. Thirty-day survival in patients with acute respiratory distress syndrome dependent on genotypes of the angiotensinogen promoter polymorphism. Kaplan-Meier estimates were used to calculate probabilities of 30-day survival. Thirty-day survival was not significantly different between angiotensin promoter polymorphism genotypes $(p=0.28)$. — : AA; …......: GG; - - - - GA.
Clinical characterisation of the ARDS patients by ACE I/D genotypes is displayed in table 2. No significant associations of $A C E$ genotypes were found with sex, age, LIS, $\mathrm{BMI}, \mathrm{Pa}, \mathrm{O}_{2} / \mathrm{FI}, \mathrm{O}_{2}$, PEEP, SAPS, SOFA or duration of ICU stay. Likewise, none of these variables were associated with AGT genotypes (table 3).

The most common causes of ARDS were pneumonia $(67 \%)$, sepsis $(24 \%)$, trauma (4\%) and aspiration (5\%), and overall survival was $68 \%$. Demographic characteristics of the ARDS patients and healthy controls are displayed in table 4 . No statistically significant differences regarding demographic characteristics between ARDS and the control group were found, except a slight difference for age. Mean ages were $43 \pm 16$ yrs in the ARDS group and $37 \pm 2$ yrs in the control group.

For both samples, genotype distributions were compatible with the Hardy-Weinberg equilibrium. ACE and AGT genotypes and allele frequencies were similar between ARDS patients and the blood donor sample (table 4). ACE and AGT genotypes were not in linkage disequilibrium and thus no interaction between $A C E$ and AGT genotypes and an association with ARDS was observed.

\section{DISCUSSION}

The present study shows for the first time in a multivariate analysis that the $\mathrm{D}$ allele of the ACE I/D polymorphism is significantly associated with an increased 30-day mortality in patients with ARDS. The HR of almost 6 for the homozygous $\mathrm{DD}$ and $\sim 5$ for the heterozygous ID genotypes compared with the II genotype, not only indicate that the D allele may have an important effect on the activity of the intrapulmonary ACE system, but also underscore the potential relevance of the ACE system for pulmonary pathology. Associations between the D allele and the development or progression of sarcoidosis [26], asthma [27] and berylliosis [28] have been described. Due to the influence of the pulmonary RAS on vascular permeability [3], vascular tone [4], fibroblast activity [5] and alveolar epithelial cell survival [6], its strong effect upon the natural course of ARDS is comprehensible. Within the lung, the pulmonary circulation is a potentially important site of RAS activation. ACE inhibitors attenuate pulmonary vasoconstriction in healthy humans and in patients with cor pulmonale [4], as do type-1 AT receptor antagonists [29]. Infusion of AT-I [30] or AT-II [3] can evoke pulmonary oedema independently of catecholamine release. AT-II may, therefore, also affect microvascular permeability. Finally, AT-II is a pro-apoptotic factor for alveolar epithelial cells in vitro [31]. The loss of an intact epithelial barrier (with implications for the movement of fluid and cells between the vascular, interstitial and alveolar spaces) is another early event in ARDS that might be influenced by the RAS. Any single mechanism or all mechanisms combined could thus impact on ARDS and its outcome.

A significant association was observed between the D allele and mortality in the patients included in the present study. Several pathways influencing the course of ARDS and/or additional mechanisms may be involved. For example, fibroproliferation could have a significant effect on outcome in ARDS $[5,32]$ and it was previously shown that AT-II is a mitogen for lung fibroblasts [5]. Furthermore, both ACE inhibitors and type-1 AT receptor antagonists attenuate 
TABLE 1 Multivariate stepwise Cox regression analysis

\begin{tabular}{lcc} 
& p-value & HR (95\% Cl) \\
\hline ACE & & \\
$\quad$ ID & & $1^{\#}$ \\
$\quad$ DD & 0.008 & $5.2(1.5-17.6)$ \\
SAPS & 0.005 & $5.7(1.7-19.2)$ \\
$\mathbf{P a}, \mathbf{O}_{\mathbf{2}} / \mathbf{F} \mathbf{1}, \mathbf{O}_{2}$ & 0.001 & $1.04(1.02-1.07)$ \\
$\mathbf{B M I}$ & 0.013 & $0.99(0.98-0.99)$ \\
$\mathbf{P E E P}$ & 0.022 & $0.86(0.75-0.98)$ \\
\hline
\end{tabular}

HR: hazard ratio; Cl: confidence interval; $A C E$ : angiotensin-converting enzyme; I: insertion; D: deletion; SAPS: Simplified Acute Physiology Score; $\mathrm{Pa}_{\mathrm{a}} \mathrm{O}_{2}$ : arterial oxygen tension; $\mathrm{Fl}_{1} \mathrm{O}_{2}$ : inspiratory oxygen fraction; $\mathrm{BMI}$ : body mass index; PEEP positive end-expiratory pressure. ${ }^{\#}$ : reference.

collagen deposition and interstitial fibrosis in experimental models of lung injury [33]. In patients with left ventricular dysfunction, ACE inhibition improved gas transfer and ventilation-perfusion-coupling by an as yet unknown mechanism [34]. It would, therefore, not be unexpected if increased ACE activity, associated with the ACE D allele, evoked opposite effects in patients with ARDS. Finally, ACE is expressed in activated alveolar macrophages [35] and lymphocytes [10]. In activated pulmonary macrophages, ACE inhibition decreased free radical expression; however, its role in modulating the inflammatory response has not been clearly defined [35].

It is well known that the I/D polymorphism accounts for $47 \%$ of the variance in plasma ACE activity in healthy white individuals, ACE activity being highest in those with the DD genotype [10]. However, ACE concentration and activity is not only influenced by genotype but also by a myriad of mechanisms, including pharmacological therapy [36] and fluid management [37]. The current authors, therefore, made no attempt to measure concentration or activity of ACE in BAL fluid or serum. Linkage and segregation analysis has shown that circulating ACE levels are influenced by a major quantitative trait locus that maps within or close to the $A C E$ gene. Multiple variants that are in linkage disequilibrium with the I/D polymorphism have been described, but none of these variants has been associated with ACE levels. In addition, it cannot be excluded that the ACE I/D polymorphism is in linkage disequilibrium with one or more variants in genes other than $A C E$ and that these yet unidentified single nucleotide polymorphisms explain the associations described here [38, 39]. Even if much information indicates AT-II as a main factor in ARDS, it should be kept in mind that ACE also degrades bradykinin, which also has an impact on vascular tone, vascular permeability and cardiac function [9].

Unexpectedly, the AGT (-6)A/G polymorphism did not affect survival during ARDS, although genotypes of this polymorphism could be associated with an increase in plasma AGT concentrations which subsequently increased AT-II generation $[16,18]$. Therefore, the present results could be explained by the hypothesis that the association seen with the ACE I/D polymorphism relates to bradykinin degradation rather than to increased AT-II formation.

An association between genotypes of the ACE I/D polymorphism and susceptibility for ARDS, as suggested by MARSHALL et al. [15], could not be confirmed in the Caucasian sample studied presently, although patient populations differed only slightly with regard to clinical characteristics, such as SAPS, LIS, $\mathrm{Pa}_{2} \mathrm{O}_{2} / \mathrm{FI}_{1} \mathrm{O}_{2}$, duration of ICU stay and overall mortality. However, one important difference may be the aetiology of respective ARDS patients. In the present study, pneumonia

TABLE 2 Angiotensin-converting enzyme genotype distribution and clinical characteristics in patients with acute respiratory distress syndrome

\begin{tabular}{|c|c|c|c|c|c|}
\hline & All & II & ID & DD & p-value \\
\hline Subjects $n$ & 84 & $23(27)$ & $36(43)$ & $25(30)$ & \\
\hline Age at diagnosis yrs & $43 \pm 16$ & $45 \pm 17$ & $43 \pm 15$ & $42 \pm 17$ & 0.74 \\
\hline LIS & $3.2 \pm 0.4$ & $3.2 \pm 0.6$ & $3.3 \pm 0.6$ & $3.15 \pm 0.5$ & 0.75 \\
\hline $\mathrm{BMI} \mathbf{k g} \cdot \mathbf{m}^{-2}$ & $26 \pm 6$ & $25 \pm 4$ & $27 \pm 6$ & $24 \pm 4$ & 0.17 \\
\hline SAPS & $50 \pm 17$ & $49 \pm 19$ & $49 \pm 16$ & $51 \pm 19$ & 0.88 \\
\hline SOFA & $12 \pm 4$ & $12 \pm 3$ & $13 \pm 4$ & $12 \pm 4$ & 0.30 \\
\hline Duration of stay days & $18(2-174)$ & $22(6-48)$ & $17(3-73)$ & $16(2-174)$ & 0.11 \\
\hline Pneumonia & 56 & 19 & 22 & 15 & \\
\hline Sepsis & 20 & 5 & 10 & 6 & \\
\hline Trauma or aspiration & 8 & 2 & 4 & 2 & 0.9 \\
\hline
\end{tabular}

Data are presented as $\mathrm{n}, \mathrm{n}(\%)$, mean $\pm \mathrm{SD}$ or median (range). I: insertion; D: deletion; M: male; F: female; LIS: lung injury score; BMI: body mass index; $\mathrm{Pa}_{\mathrm{a}} \mathrm{O}_{2}$ : arterial oxygen tension; $\mathrm{Fl}_{1} \mathrm{O}_{2}$ : inspiratory oxygen fraction; PEEP: positive end-expiratory pressure; SAPS: Simplified Acute Physiology Score; SOFA: sequential organ failure assessment. p-Values were calculated using the Chi-squared test for categorical variables, ANOVA for continuous parametric variables and the Kruskal-Wallis test for continuous nonparametric variables. 


\begin{tabular}{|c|c|c|c|c|c|}
\hline \multirow[t]{2}{*}{ TABLE 3} & \multicolumn{5}{|c|}{$\begin{array}{l}\text { Angiotensinogen genotype distribution and } \\
\text { clinical characteristics in patients with acute } \\
\text { respiratory distress syndrome }\end{array}$} \\
\hline & All & GG & GA & AA & p-value \\
\hline Subjects $n$ & 84 & $24(29)$ & $49(58)$ & $11(13)$ & \\
\hline Sex $M / F$ & $43 / 41$ & $18 / 6(21 / 7)$ & 21/28 (25/33) & 4/7 (5/8) & 0.028 \\
\hline $\begin{array}{l}\text { Age at diagnosis } \\
\text { yrs }\end{array}$ & is $43 \pm 16$ & $42 \pm 15$ & $44 \pm 17$ & $44 \pm 14$ & 0.77 \\
\hline LIS & $3.2 \pm 0.4$ & $3.2 \pm 0.5$ & $3.3 \pm 0.5$ & $3.3 \pm 0.5$ & 0.53 \\
\hline BMI $\mathrm{kg} \cdot \mathrm{m}^{-2}$ & $26 \pm 6$ & $25 \pm 3$ & $26 \pm 5$ & $27 \pm 6$ & 0.10 \\
\hline $\mathrm{Pa}, \mathrm{O}_{2} / \mathrm{Fl}_{1} \mathrm{O}_{2} \mathrm{mmHg}$ & $\lg 116 \pm 65$ & $119 \pm 66$ & $113 \pm 65$ & $125 \pm 76$ & 0.27 \\
\hline PEEP mbar & $16 \pm 4$ & $15 \pm 5$ & $17 \pm 4$ & $15 \pm 6$ & 0.75 \\
\hline SAPS & $50 \pm 17$ & $51 \pm 19$ & $47 \pm 16$ & $51 \pm 19$ & 0.55 \\
\hline SOFA & $12 \pm 4$ & $12 \pm 4$ & $12 \pm 3$ & $14 \pm 3$ & 0.19 \\
\hline $\begin{array}{l}\text { Duration of stay } \\
\text { days }\end{array}$ & y $18(2-174)$ & $26(6-48)$ & $23(3-73)$ & $34(2-174)$ & 0.11 \\
\hline Pneumonia & 56 & 14 & 33 & 9 & \\
\hline Sepsis & 20 & 6 & 12 & 2 & \\
\hline $\begin{array}{l}\text { Trauma or } \\
\text { aspiration }\end{array}$ & 8 & 4 & 4 & 0 & 0.52 \\
\hline
\end{tabular}

Data are presented as $\mathrm{n}, \mathrm{n}(\%)$, mean $\pm \mathrm{SD}$ or median (range). M: male; $\mathrm{F}$ : female; LIS: lung injury score; BMl: body mass index; $\mathrm{Pa}_{\mathrm{a}} \mathrm{O}_{2}$ : arterial oxygen tension; $\mathrm{Fl}, \mathrm{O}_{2}$ : inspiratory oxygen fraction; PEEP: positive end-expiratory pressure; SAPS: Simplified Acute Physiology Score; SOFA: sequential organ failure assessment. $p$-Values were calculated using the Chi-squared test for categorical variables, ANOVA for continuous parametric variables and the Kruskal-Wallis test for continuous nonparametric variables.

was the underlying cause of ARDS in $60 \%$ of patients, while pneumonia was diagnosed in only $30 \%$ of cases in the sample of MARSHALL et al. [15]. Thus, it could be speculated that the association between the D allele and susceptibility for ARDS exists only in secondary (nonpneumonia) ARDS. This hypothesis appears to be supported by data generated with regard to the Asian epidemic of Severe Acute Respiratory Syndrome (SARS), as the susceptibility for ARDS was not associated with the D allele of the ACE polymorphism [40].

Despite 30 yrs of research into the mechanisms and consequences of ARDS, efforts to identify a reliable, pulmonaryspecific risk factor for death have been disappointing. Variables that are independently associated with mortality are not specific for abnormalities of pulmonary pathophysiology, such as sepsis, nonpulmonary organ system dysfunction, age or cirrhosis [41, 42]. Although indices of hypoxaemia, such as $\mathrm{Pa}_{1} \mathrm{O}_{2}, \mathrm{FI}, \mathrm{O}_{2}$ or the $\mathrm{Pa}_{1} \mathrm{O}_{2} / \mathrm{FI}, \mathrm{O}_{2}$ ratio, were initially thought to have prognostic value $[42,43]$, subsequent studies established that these variables were not independently associated with the risk of death when they were measured early in the course of ARDS [41, 42]. Furthermore, the majority of ARDS patients eventually die of multiple organ failure and the present study cannot explain why the $A C E$ gene polymorphism affects outcome. Also, the current authors do not know whether another pathway dependent on genotypes of the ACE polymorphism is triggered. For instance, there is laboratory evidence of involvement of angiotensin in the activation of nuclear factor- $\kappa \mathrm{B}$. This may suggest a pro-inflammatory effect for

\begin{tabular}{|c|c|c|c|}
\hline \multirow[t]{2}{*}{ TABLE 4} & \multicolumn{3}{|c|}{$\begin{array}{l}\text { Genotype frequencies of the angiotensin- } \\
\text { converting enzyme (ACE) insertion/deletion (I/D) } \\
\text { and the angiotensinogen (AGT) (-6)A/G promoter } \\
\text { polymorphism and demographic characteristics } \\
\text { in acute respiratory distress syndrome patients } \\
\text { and in healthy blood donors }\end{array}$} \\
\hline & Patients & Controls & $p$-value \\
\hline All & 84 & 200 & \\
\hline \multicolumn{4}{|l|}{$A C E$} \\
\hline$\|$ & $23(27)$ & $39(20)$ & \\
\hline ID & $36(43)$ & $106(53)$ & \\
\hline DD & $25(30)$ & 55 (27) & 0.22 \\
\hline \multicolumn{4}{|l|}{ AGT } \\
\hline GG & $24(29)$ & $72(36)$ & \\
\hline$A G$ & $49(58)$ & $92(46)$ & \\
\hline AA & $11(13)$ & $36(18)$ & 0.28 \\
\hline Age yrs & $43 \pm 16$ & $37 \pm 2$ & 0.001 \\
\hline BMI $\mathbf{k g} \cdot \mathrm{m}^{-2}$ & $26 \pm 6$ & $25 \pm 4$ & 0.578 \\
\hline Sex M/F & $43 / 41$ & $123 / 72$ & 0.06 \\
\hline
\end{tabular}

the development or aggravation of the systemic inflammatory response syndrome [44]. However, these are only speculations. Furthermore, ARDS, by definition, encompasses a relatively small range of the phenotype pulmonary dysfunction, with almost all patients showing severe dysfunction, pulmonary hypertension and high shunt. Thus, it would be unexpected that a correlation of phenotype (shunt, and the like) and genotype be uncovered.

Although all ARDS patients were treated with a standardised multimodal concept which included analgosedation, fluid, ventilation, haemodynamic, antibiotic and diagnostic management, it cannot be excluded, due to the multifactorial nature of the disorder, that unknown, potentially confounding, factors still exist. Thus, the results of the present study should not be over-interpreted. However, the present investigation shows that the ACE I/D polymorphism affects pulmonary disorders and also underscores the potential relevance of the ACE system for ARDS.

In conclusion, the present findings could have clinical impact in the future. This impact could include identification of novel candidate genes in the bradykinin pathway, tailoring of drug therapy related to the renin-angiotensin system and stratification of patients for clinical trials.

\section{ACKNOWLEDGEMENTS}

The authors would like to thank U. Costabel (Essen, Germany) for critical reading of the manuscript.

\section{REFERENCES}

1 Matthay MA, Zimmerman GA, Esmon C, et al. Future research directions in acute lung injury: summary of a 
National Heart, Lung, and Blood Institute working group. Am J Respir Crit Care Med 2003; 167: 1027-1035.

2 Villar J, Flores C, Mendez-Alvarez S. Genetic susceptibility to acute lung injury. Crit Care Med 2003; 31: S272-S275.

3 Yamamoto T, Wang L, Shimakura K, Sanaka M, Koike Y, Mineshita S. Angiotensin II-induced pulmonary edema in a rabbit model. Jpn J Pharmacol 1997; 73: 33-40.

4 Kiely DG, Cargill RI, Wheeldon NM, Coutie WJ, Lipworth BJ. Haemodynamic and endocrine effects of type 1 angiotensin II receptor blockade in patients with hypoxaemic cor pulmonale. Cardiovasc Res 1997; 33: 201-208.

5 Marshall RP, Puddicombe A, Cookson WO, Laurent GJ. Adult familial cryptogenic fibrosing alveolitis in the United Kingdom. Thorax 2000; 55: 143-146.

6 Fourrier F, Chopin C, Wallaert B, Mazurier C, Mangalaboyi J, Durocher A. Compared evolution of plasma fibronectin and angiotensin-converting enzyme levels in septic ARDS. Chest 1985; 87: 191-195.

7 Kageyama R, Ohkubo H, Nakanishi S. Primary structure of human preangiotensinogen deduced from the cloned cDNA sequence. Biochemistry 1984; 23: 3603-3609.

8 Nakanishi S, Ohkubo H, Nawa H, Kitamura N, Kageyama R, Ujihara M. Angiotensinogen and kininogen: cloning and sequence analysis of the cDNAs. Clin Exp Hypertens A 1983; 5: 997-1003.

9 Liu YH, Yang XP, Mehta D, Bulagannawar M, Scicli GM, Carretero OA. Role of kinins in chronic heart failure and in the therapeutic effect of ACE inhibitors in kininogendeficient rats. Am J Physiol Heart Circ Physiol 2000; 278: H507-H514.

10 Rigat B, Hubert C, Alhenc-Gelas F, Cambien F, Corvol P, Soubrier F. An insertion/deletion polymorphism in the angiotensin I-converting enzyme gene accounting for half the variance of serum enzyme levels. J Clin Invest 1990; 86: 1343-1346.

11 Idell S, Kueppers F, Lippmann M, Rosen H, Niederman M, Fein A. Angiotensin converting enzyme in bronchoalveolar lavage in ARDS. Chest 1987; 91: 52-56.

12 Wenz M, Steinau R, Gerlach H, Lange M, Kaczmarczyk G. Inhaled nitric oxide does not change transpulmonary angiotensin II formation in patients with acute respiratory distress syndrome. Chest 1997; 112: 478-483.

13 Wiberg-Jorgensen F, Klausen NO, Hald A, Qvist J, Giese J, Damkjaer Neilsen M. Pulmonary angiotensin II production in respiratory failure. Clin Physiol 1983; 3: 59-67.

14 Baudin B. New aspects on angiotensin-converting enzyme: from gene to disease. Clin Chem Lab Med 2002; 40: 256-265.

15 Marshall RP, Webb S, Bellingan GJ, et al. Angiotensin converting enzyme insertion/deletion polymorphism is associated with susceptibility and outcome in acute respiratory distress syndrome. Am J Respir Crit Care Med 2002; 166: 646-650.

16 Gould $A B$, Green D. Kinetics of the human renin and human substrate reaction. Cardiovasc Res 1971; 5: 86-89.

17 Inoue I, Nakajima T, Williams CS, et al. A nucleotide substitution in the promoter of human angiotensinogen is associated with essential hypertension and affects basal transcription in vitro. J Clin Invest 1997; 99: 1786-1797.
18 Jeunemaitre $X$. Polymorphismes génétiques du système rénine-angiotensine: Actualités sur la Système RénineAngiotensine-Aldostérone. [Genetic polymorphisms in the renin-angiotensin system]. Thérapie 1998; 53: 271-277.

19 Bernard GR, Artigas A, Brigham KL, et al. The AmericanEuropean Consensus Conference on ARDS. Definitions, mechanisms, relevant outcomes, and clinical trial coordination. Am J Respir Crit Care Med 1994; 149: 818-824.

20 Bone RC. The sepsis syndrome. Definition and general approach to management. Clin Chest Med 1996; 17: 175-181.

21 Le Gall JR, Lemeshow S, Saulnier F. A new Simplified Acute Physiology Score (SAPS II) based on a European/North American multicenter study. JAMA 1993; 270: 2957-2963.

22 Peres Bota D, Melot C, Lopes Ferreira F, Nguyen Ba V, Vincent JL. The Multiple Organ Dysfunction Score (MODS) versus the Sequential Organ Failure Assessment (SOFA) score in outcome prediction. Intensive Care Med 2002; 28: 1619-1624.

23 Siffert W, Forster P, Jockel KH, et al. Worldwide ethnic distribution of the $\mathrm{G}$ protein $\beta 3$ subunit $825 \mathrm{~T}$ allele and its association with obesity in Caucasian, Chinese, and Black African individuals. J Am Soc Nephrol 1999; 10: 1921-1930.

24 Lindpaintner K, Pfeffer MA, Kreutz R, et al. A prospective evaluation of an angiotensin-converting-enzyme gene polymorphism and the risk of ischemic heart disease. $N$ Engl J Med 1995; 332: 706-711.

25 Ahmadian A, Gharizadeh B, Gustafsson AC, et al. Singlenucleotide polymorphism analysis by pyrosequencing. Anal Biochem 2000; 280: 103-110.

26 Furuya K, Yamaguchi E, Kawakami Y. [Angiotensinconverting enzyme (ACE) polymorphism and serum ACE activities in sarcoidosis]. Nippon Rinsho 1994; 52: 1561-1566.

27 Benessiano J, Crestani B, Mestari F, et al. High frequency of a deletion polymorphism of the angiotensin-converting enzyme gene in asthma. J Allergy Clin Immunol 1997; 99: 53-57.

28 Maier LA, Raynolds MV, Young DA, Barker EA, Newman LS. Angiotensin-1 converting enzyme polymorphisms in chronic beryllium disease. Am J Respir Crit Care Med 1999; 159: 1342-1350.

29 Cargill RI, Kiely DG, Clark RA, Lipworth BJ. Hypoxaemia and release of endothelin-1. Thorax 1995; 50: 1308-1310.

$30 \mathrm{Xu} \mathrm{ZH}$, Shimakura K, Yamamoto T, Wang LM, Mineshita S. Pulmonary edema induced by angiotensin I in rats. Jpn J Pharmacol 1998; 76: 51-56.

31 Wang R, Zagariya A, Ang E, Ibarra-Sunga O, Uhal BD. Fasinduced apoptosis of alveolar epithelial cells requires ANG II generation and receptor interaction. Am J Physiol 1999; 277: L1245-L1250.

32 Chesnutt AN, Matthay MA, Tibayan FA, Clark JG. Early detection of type III procollagen peptide in acute lung injury. Pathogenetic and prognostic significance. Am J Respir Crit Care Med 1997; 156: 840-845.

33 Ward WF, Molteni A, Ts'ao CH, Hinz JM. Captopril reduces collagen and mast cell accumulation in irradiated rat lung. Int J Radiat Oncol Biol Phys 1990; 19: 1405-1409.

34 Guazzi M, Melzi G, Marenzi GC, Agostoni P. Angiotensinconverting enzyme inhibition facilitates alveolar-capillary gas transfer and improves ventilation-perfusion coupling in patients with left ventricular dysfunction. Clin Pharmacol Ther 1999; 65: 319-327. 
35 Suzuki M, Teramoto S, Katayama H, Ohga E, Matsuse T, Ouchi Y. Effects of angiotensin-converting enzyme (ACE) inhibitors on oxygen radical production and generation by murine lung alveolar macrophages. J Asthma 1999;36: 665-670.

36 Fishel RS, Eisenberg S, Shai SY, Redden RA, Bernstein KE, Berk BC. Glucocorticoids induce angiotensin-converting enzyme expression in vascular smooth muscle. Hypertension 1995; 25: 343-349.

37 Zhao X, White R, Huang BS, Van Huysse J, Leenen FH. High salt intake and the brain renin-angiotensin system in Dahl salt-sensitive rats. J Hypertens 2001; 19: 89-98.

38 Keavney B, McKenzie CA, Connell JM, et al. Measured haplotype analysis of the angiotensin-I converting enzyme gene. Hum Mol Genet 1998; 7: 1745-1751.

39 Brand E, Chatelain N, Keavney B, et al. Evaluation of the angiotensinogen locus in human essential hypertension: a European study. Hypertension 1998; 31: 725-729.

40 Chan KC, Tang NL, Hui DS, et al. Absence of association between angiotensin converting enzyme polymorphism and development of adult respiratory distress syndrome in patients with severe acute respiratory syndrome: a case control study. BMC Infect Dis 2005; 5: 26.

41 Doyle RL, Szaflarski N, Modin GW, Wiener-Kronish JP, Matthay MA. Identification of patients with acute lung injury. Predictors of mortality. Am J Respir Crit Care Med 1995; 152: 1818-1824.

42 Zilberberg MD, Epstein SK. Acute lung injury in the medical ICU: comorbid conditions, age, etiology, and hospital outcome. Am J Respir Crit Care Med 1998; 157: 1159-1164.

43 Sloane PJ, Gee MH, Gottlieb JE, et al. A multicenter registry of patients with acute respiratory distress syndrome. Physiology and outcome. Am Rev Respir Dis 1992; 146: 419-426.

44 Han Y, Runge MS, Brasier AR. Angiotensin II induces interleukin-6 transcription in vascular smooth muscle cells through pleiotropic activation of nuclear factor- $\kappa \mathrm{B}$ transcription factors. Circ Res 1999; 84: 695-703. 